\title{
Research Tasks of Mechanical Strength and Fracture of Cast-Resin Insulated Busbar Systems
}

\author{
Egor V. Moskvichev*, \\ Yuliya F. Filippova and Nikita V. Eremin \\ Ltd "Digital Mind Development" \\ 53 Mira, Krasnoyarsk, 660049, Russia
}

Received 18.11.2016, received in revised form 27.12.2016, accepted 09.01.2017

Research tasks of mechanical strength of cast-resin insulated busbar systems working in Siberia are formulated. The research is aimed to provide the insulation strength at various operating factors. As the methods of investigation a numerical analysis of stress-strain state and mechanical testing of insulation material are considered. Numerical analysis consists in solving the joint problem of heat conduction and thermoelasticity by finite element method. Formulated list of material tests includes the determination of physical, mechanical and strength properties according to standardized procedures.

Keywords: busbar systems, insulation, strength, modelling, testing.

Citation: Moskvichev E.V., Filippova Yu.F., Eremin N.V. Research tasks of mechanical strength and fracture of cast-resin insulated busbar systems, J. Sib. Fed. Univ. Eng. technol., 2017, 10(1), 17-23. DOI: 10.17516/1999-494X-2017-10-1-17-23.

\section{Задачи исследования механической прочности и условий разрушения токопроводов \\ с литой изоляцией}

\author{
Е.В. Москвичев, Ю.Ф. Филиппова, Н.В. Еремин \\ ООО «Диджитал Майнд Девелопмент» \\ Россия, 660049, Красноярск, Мира, 53
}

Сформулированы задачи исследования механической прочности литых токопроводов, работающих в условиях Сибири. Исследование направлено на обеспечение прочности изоляиии при различных факторах эксплуатачии. В качестве методов исследования рассмотрень численный анализ напряженно-деформированного состояния и испытания материала изоляиии. Численный анализ заключается в решении связанной задачи теплопроводности и термоупругости методом конечных элементов. Сформулированный перечень испытаний

(C) Siberian Federal University. All rights reserved

* Corresponding author E-mail address: jugr@icm.krasn.ru, julfila@rambler.ru 
включает в себя определение физико-механических и прочностных свойств согласно стандартизованным методикам.

Ключевые слова: токопровод, изолячии, прочность, моделирование, испьтания.

\section{Введение}

В современных энергетических комплексах широкое применение получают токопроводы с литой изоляцией. Данные токопроводы обладают следующими преимуществами: компактность размеров, произвольная геометрическая форма, прочность, устойчивость к перегрузкам и др. [1]. Несмотря на декларируемые высокие свойства литых токопроводов, опыт их эксплуатации в условиях Сибири свидетельствует о возможности их повреждения. В связи с этим в работе [2] рассматривался опыт постановки и решения прикладных задач конструкционной прочности литых токопроводов в рамках проведения научно-технической экспертизы при аварийной ситуации. Выполненный анализ прочности элементов токопровода обеспечил получение достоверных выводов о возможности трещинообразования и разрушения изоляции токопроводов при эксплуатации в широком диапазоне температурных условий. Это определило необходимость развития расширенного научного подхода к разработке задач исследования механической прочности и разрушения токопроводов с литой изоляцией. К таким задачам относятся:

- формулировка эксплуатационных условий и нагрузок, при которых возможно разрушение литой изоляции токопровода;

- прочностной анализ токопровода при различных условиях эксплуатации с применением методов численного моделирования;

- обоснование экспериментальных исследований физических и механических свойств материала изоляции токопровода.

\section{Эксплуатационные факторы разрушения литой изоляции токопровода}

Методические подходы к решению указанных задач рассматривались на примере протяженного литого токопровода сложной конфигурации, эксплуатирующегося на открытом воздухе в температурных условиях Сибири при номинальном токе 6000 А и напряжении 6 кВ. Трасса токопровода состояла из прямолинейных, T-образных, Z-образных и Г-образных секций заводского изготовления, а также компенсаторов температурных расширений. Токопровод имел три токопроводящие шины, находящиеся в литой изоляции, изготовленной на основе полимерного компаунда.

При эксплуатации токопровода были выявлены трещины в литой изоляции, которые привели к возникновению аварийной ситуации [3]. Анализ зон трещинообразования (рис. 1) показал наличие трещин следующих типов:

- нормальные к продольной оси элемента конструкции, образовавшиеся при изгибе;

- возникающие на растянутой поверхности элемента конструкции, направленные первоначально нормально к ней, а затем распространяющиеся под наклоном к продольной оси, - образуются в зоне совместного действия изгибающих моментов и поперечных сил при преобладании вклада изгибающих моментов;

$$
-18-
$$



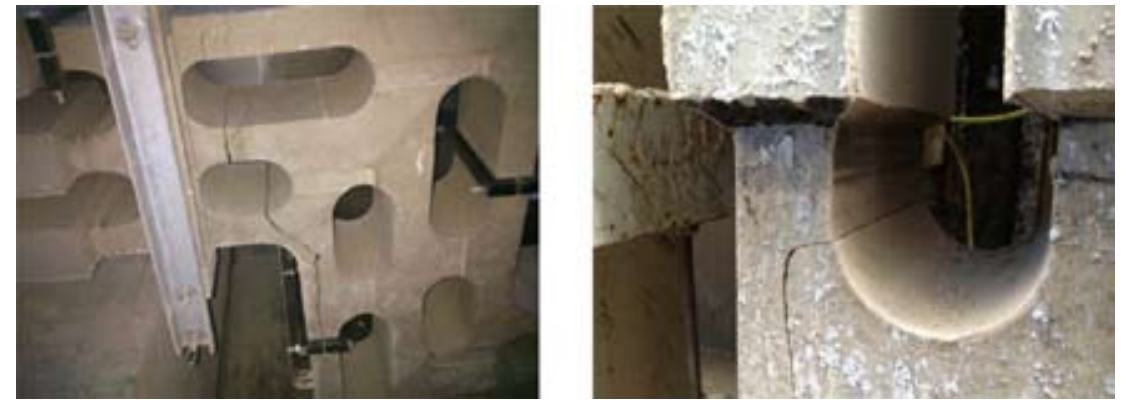

Рис. 1. Трещины в изоляции токопровода

- возникающие и распространяющиеся под наклоном к продольной оси элемента - образуются в зоне совместного действия изгибающих моментов и поперечных сил при преобладании вклада поперечных сил.

Анализ причин возникновения трещин позволил выявить следующие основные эксплуатационные факторы, приводящие к разрушению изоляции токопровода:

- температурные воздействия;

- весовая нагрузка;

- нагрузка от самокомпенсации температурных расширений.

Температурные воздействия обусловлены нагревом токопроводящих шин при протекании по ним электрического тока и температурой окружающей среды. В условиях Сибири температура окружающего воздуха может изменяться от минус 60 до $40{ }^{\circ} \mathrm{C}$, тогда как температура проводящей шины может достигать $50^{\circ} \mathrm{C}$. Особую опасность при этом имеет неравномерный нагрев, который вызывает температурные напряжения в стенках изоляции токопровода и возникает, как правило, при нестационарном температурном режиме (прогрев, охлаждение, аварийная ситуация т.п.). Учет неравномерного нагрева токопровода имеет особое значение в связи с большой толщиной изоляции, поэтому возникающие градиенты температур в изоляции токопровода должны учитываться при анализе прочности.

Компонентами весовой нагрузки являются собственный вес металла токопроводящих шин и вес изоляции токопровода. Эта нагрузка может быть распределенной как вдоль, так и поперек секций токопровода в зависимости от конфигурации трассы. Для защиты токопровода от воздействия весовой нагрузки применяют различные промежуточные опоры, которые оказывают значительное влияние на эксплуатационную повреждаемость токопровода. Ошибки проектирования и монтажа опорно-подвесной системы могут приводить к провисанию участков токопровода, возникновению нерасчетных механических нагрузок и, как следствие, - к разрушению.

Самокомпенсация температурных расширений обусловлена температурным расширением секций токопровода. Расширение поглощается участками токопровода, что вызывает силовое деформирование. Возникающие при этом усилия и напряжения в местах креплений, заделок и защемлений могут превышать расчетные. Поэтому при проектировании протяженных токопроводов значительное внимание следует уделять снижению компенсационных нагрузок и расчету достаточного количества компенсаторов температурных расширений. Так, согласно

$$
-19-
$$


СТО 56947007-29.120.60.106-2011 «Токопроводы с литой (твёрдой) изоляцией на напряжение 6-35 кВ. Технические требования» регламентируется установка компенсаторов температурных расширений с интервалом не более 10 м.

Совместное действие рассмотренных нагрузок наряду с ошибками проектирования и дефектами монтажа приводит к наиболее неблагоприятным условиям возникновения разрушений.

\section{Особенности анализа механической прочности токопровода}

Для решения рассматриваемой проблемы трещинообразования был сформирован комплекс расчетно-экспериментальных исследований, направленных на обеспечение прочности токопроводов с литой изоляцией. Данный комплекс включает в себя:

- расчет температурных полей в секциях токопровода при различных условиях эксплуатации;

- расчет напряжено-деформированного состояния протяженного участка трассы токопровода и его отдельных элементов;

- экспериментальную оценку физико-механических свойств материала изоляции токопровода.

Все элементы токопровода подчиняются законам теплопроводности. Однако сложная геометрия секций токопровода, наличие нескольких токопроводящих шин не позволяют получить достоверные данные о распределении температур внутри секций путем простых аналитических расчетов. В связи с этим целесообразно решать задачи стационарной теплопроводности численно, что позволяет определить установившиеся поля распределения температур в сечениях секций в зависимости от задаваемых температур токопроводящих шин и внешней среды с учетом теплопроводности материалов.

Примеры полученных путем численного моделирования полей распределений температур для различных секций представлены на рис. 2. Эти результаты являются исходными данными для расчета напряженно-деформированного состояния токопровода при совместном термомеханическом нагружении.

На следующем этапе для определения температурных деформаций и напряжений решается связанная задача стационарной теплопроводности и термоупругости (рис. 3). Полученные поля распределения температур сохраняются в базе данных решаемой задачи, и с учетом

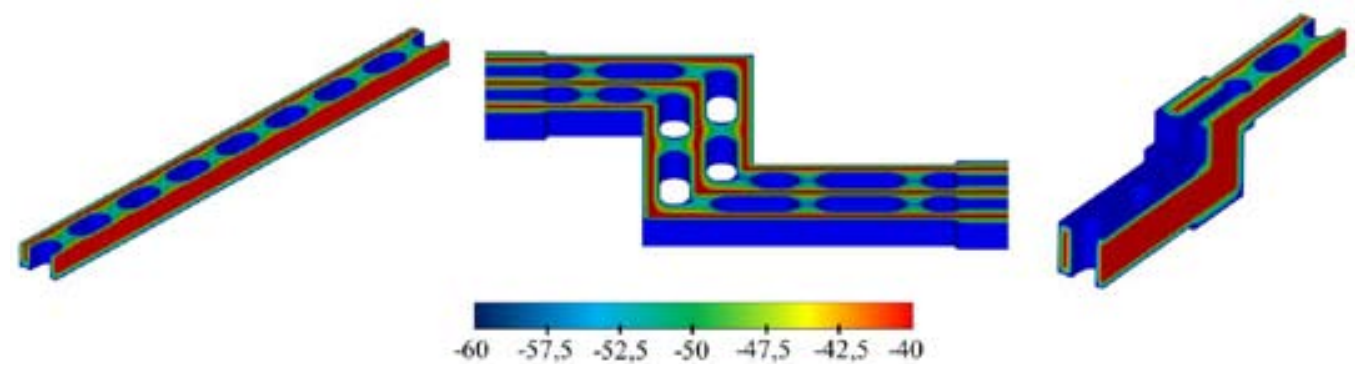

Рис. 2. Поля распределений температур в сечениях секций токопровода при температуре окружающей среды минус $60^{\circ} \mathrm{C}$ 


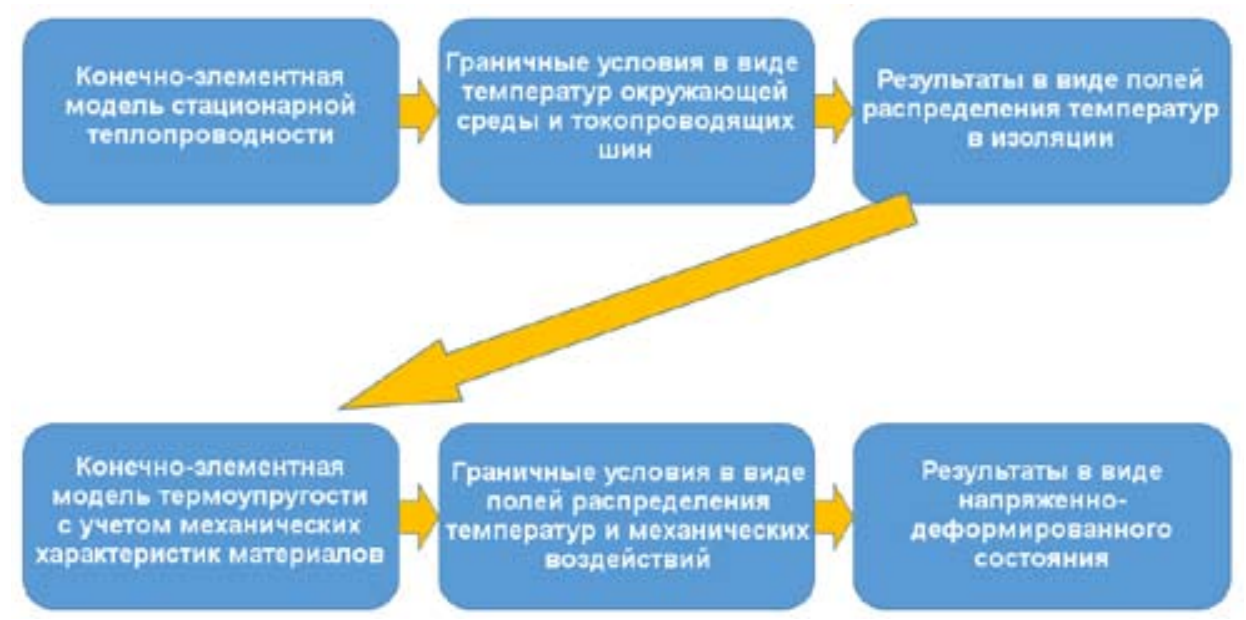

Рис. 3. Логическая схема решения связанной задачи стационарной теплопроводности и термоупругости

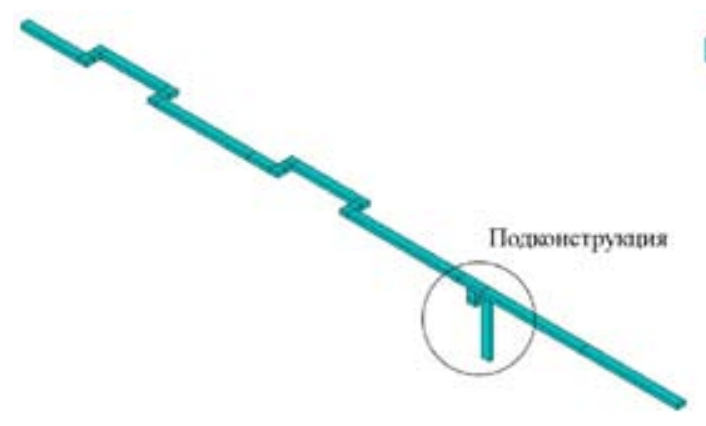

a)

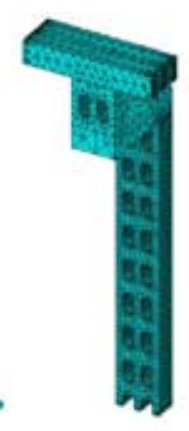

6)

Рис. 4. Стержневая модель трассы токопровода (а) и модель подконструкции (б)

значений коэффициентов линейного расширения материалов определяются смещения узлов конечно-элементной модели, вызывающие термические деформации и напряжения.

Для расчета напряженно-деформированного состояния токопровода с учетом локальных геометрических особенностей (элементы крепления, сочленения секций, прохождение проемов перекрытий и т.п.) была разработана конечно-элементная модель участка трассы токопровода с применением метода подконструкций [4].

Метод подконструкций заключается в многоуровневом моделировании. На первом этапе выполняется глобальный анализ напряженно-деформированного состояния конструкции с использованием пространственной стержневой модели участка трассы токопровода (рис. $4 a$ ), а затем осуществляется локальное моделирование элемента токопровода (рис. 4б) объемными конечными элементами с мелким сеточным разбиением. При анализе стержневой модели определяются смещения конечно-элементных узлов на границе области подконструкции. Затем эти смещения переносятся в качестве граничных условий на поверхность подконструкции.

Согласно принципу Сен-Венана, лежащему в основе данного метода, напряженнодеформированное состояние в конструктивных элементах отдельных секций не оказывает 
влияния на напряженно-деформированное состояние участка токопровода в целом. В связи с этим метод подконструкций позволяет эффективно проводить многовариантные расчеты, не изменяя полную конечно-элементную модель трассы токопровода, и обеспечивает достаточную точность решения за приемлемое время.

\section{Обоснование экспериментальных исследований физическо-механических свойств материала изоляции токопровода}

При выборе методов исследования свойств конструкционного материала важно обеспечить их соответствие характеру нагружения элемента конструкции, изготавливаемого из этого материала. Согласно рассмотренным условиям нагружения токопровода целесообразны исследования следующих физико-механических свойств материала изоляции:

- плотность;

- коэффициент линейного теплового расширения;

- упругие свойства;

- прочностные свойства.

При этом необходимо учитывать возможную зависимость этих характеристик от температуры, которая для токопровода, работающего в условиях Сибири, может изменяться от минус 60 до $40{ }^{\circ} \mathrm{C}$. Кроме того, токопроводы относятся к объектам технического надзора и методы испытаний для материалов, используемых в токопроводах, должны соответствовать нормам и стандартам, применяемым в инженерной практике.

Изоляция литых токопроводов представляет собой получаемый методом литья эпоксидный компаунд, насыщенный мелкозернистыми частицами инертных материалов [5]. Для такого материала отсутствуют специальные методы испытаний и соответствующие нормативные документы. Наличие эпоксидного связующего позволяет отнести компаунд к классу нетермореактивных пластмасс, а мелкозернистый наполнитель, взаимодействующий со связующим, дает основание рассматривать компаунд как наполненный (гомогенный) композитный материал с армирующими компонентами в виде частиц.

Для токопроводов зарубежного производства методы испытаний изоляции регламентируется такими стандартами, как DIN 52452, DIN 53452, ASTM D-638, применяемыми для пластмасс. Анализ же отечественных нормативных документов на проведение испытаний дает основания отдать предпочтение следующим методам:

- для исследования плотности - ГОСТ 15139-69 «Пластмассы. Методы определения плотности (объемной массы)»;

- для исследования коэффициента линейного расширения - ГОСТ 15173-70 «Пластмассы. Метод определения среднего коэффициента линейного теплового расширения»;

- для исследования модуля упругости и прочностных характеристик - ГОСТ 25.601-82 «Расчеты и испытания на прочность. Методы механических испытаний композиционных материалов с полимерной матрицей (композитов). Метод испытания плоских образцов на растяжение при нормальной, повышенной и пониженной температурах» и ГОСТ 25.604-82 «Расчеты и испытания на прочность. Методы механических испытаний композиционных материалов с полимерной матрицей (композитов). Метод испытания на изгиб при нормальной, повышенной и пониженной температурах». 
Выбор метода испытаний для исследования упругих и прочностных свойств (растяжение или изгиб) может быть обусловлен факторами нагружения конкретных участков токопровода и возможностью возникновения того или иного типа трещин. Анализ результатов технической экспертизы, представленных в работе [2], является аргументом в пользу выбора метода испытаний на изгиб.

\section{Заключение}

Токопроводы с литой изоляцией могут быть подвержены разрушению в процессе эксплуатации при неблагоприятном сочетании факторов нагружения, особенно при наличии нарушений технологии производства и дефектов монтажа. Анализ причин таких разрушений при проведении технической экспертизы должен основываться на инженерных методах, подкрепленных достоверными исследованиями.

Исследование механической прочности и разрушения токопроводов с литой изоляцией является комплексной задачей, требующей научно обоснованного расчетно-экспериментального подхода. Накопленный научный и инженерный опыт расчета и анализа прочности несущих конструкций технических систем [4-6] позволил разработать такой подход. Он основывается на методах численного анализа напряженно-деформированного состояния и на стандартизованных методах испытания конструкционных материалов.

Исследование выполнено при финансовой поддержке РФФИ, Правительства Красноярского края и Красноярского краевого фонда науки в рамках научного проекта № 16-48-243022.

\section{Список литературы}

[1] Даниелян Н. Опыт применения литых токопроводов в России. Энергетика и промышленность России, 2014, 7, 34-35 [Danielyan N. Experience of using cast resin insulated busbars in Russia. Power and industry of Russia, 2014, 7, 34-35 (in Russian)].

[2] Доронин С.В., Москвичев Е.В., Косолапов Д.В., Осокин В.И. Прикладные задачи научнотехнической экспертизы прочности литых токопроводов. Энергобезопасность и энергосбережение, 2015, 6, 45-49 [Doronin S.V., Moskvichyov E.V., Kosolapov D.V., Osokin V.I. On scientific and technical inspections of insulated cast-resin busbars durability. Energy Safety and Energy Economy, 2015, 6, 45-49 (in Russian)].

[3] Постановление № 5-30/2014 Кежемского районного суда Красноярского края [Тhе decision number 5-30/2014 of the Kezhemsky district court of Krasnoyarsk krai (in Russian)].

[4] Доронин С.В., Лепихин А.М., Москвичев В.В., Шокин Ю.И. Моделирование прочности и разрушения несущиих конструкций технических систем. Новосибирск: Наука, 2005, 250 c. [Doronin S.V., Lepikhin A.M., Moskvichev V.V., Shokin Yu.I. Modeling of strength and fracture of bearing structures of technical systems. Novosibirsk: Nauka, 2005, 250 p.]

[5] Сибикин Ю.Д. Электрические подстанщии. М.: Директ-Медиа, 2014, 414 с. [Sibikin U.D. Electrical substations. Moscow, Direct-Media, 2014, 414 p. (in Russian)]

[6] Живучесть паропроводов стареющих тепловых электростанщий. Под ред. Израилева Ю.Л., Хромченко Ф.А. М.: ТОРУС ПРЕСС, 2002, 616 с. [Vitality of steam lines of aging thermal power plants. Ed. Izrailev Y.L., Khromchenko F.A. Moscow, Torus Press, 2002, 616 p. (in Russian)] 